TITLE:

\title{
Minimal-disturbance seismic rehabilitation of steel moment- resisting frames using light-weight steel elements
}

\section{AUTHOR(S):}

Kurata, Masahiro; Sato, Miho; Zhang, Lei; Lavan, Oren; Becker, Tracy; Nakashima, Masayoshi

\section{CITATION:}

Kurata, Masahiro ... [et al]. Minimal-disturbance seismic rehabilitation of steel momentresisting frames using light-weight steel elements. Earthquake Engineering and Structural Dynamics 2016, 45(3): 383-400

\section{ISSUE DATE:}

2016-03

URL:

http://hdl.handle.net/2433/265274

\section{RIGHT:}

This is the peer reviewed version of the following article: [Minimal-disturbance seismic rehabilitation of steel momentresisting frames using light-weight steel elementst, Earthquake Engineering and Structural Dynamics, 45(3) 383-400], which has been published in final form at [https://doi.org/10.1002/eqe.2662]. This article may be used for noncommercial purposes in accordance with Wiley Terms and Conditions for Use of Self-Archived Versions. This article may not be enhanced, enriched or otherwise transformed into a derivative work, without express permission from Wiley or by statutory rights under applicable legislation. Copyright notices must not be removed, obscured or modified. The article must be linked to Wiley's version of record on Wiley Online Library and any embedding, framing or otherwise making available the article or pages thereof by third parties from platforms, ser ... 


\title{
Minimal-Disturbance Seismic Rehabilitation of Steel Moment-Resisting Frames
} using Light-weight Steel Elements

\author{
Masahiro Kurata ${ }^{1}$, Miho Sato ${ }^{2}$, Zhang Lei ${ }^{2}$, Oren Lavan ${ }^{3}$, \\ Tracy Becker ${ }^{4}$, Masayoshi Nakashima ${ }^{1}$ \\ ${ }^{1}$ Disaster Prevention Research Institute, Kyoto University, Kyoto, Japan \\ ${ }^{2}$ Architecture and Architectural Engineering, Kyoto University, Kyoto, Japan \\ ${ }^{3}$ Civil and Environmental Engineering, Technion - Israel Institute of Technology, Haifa, \\ Israel \\ ${ }^{4}$ Civil Engineering, McMaster University, Ontario, Canada
}

\begin{abstract}
This paper presents a rehabilitation technique developed under a design and construction scheme, termed minimal-disturbance seismic rehabilitation. This scheme pursues enhancing the seismic performance of buildings with the intention of improving the continuity of business while minimizing obstruction of the visual and physical space of building users and the use of heavy construction equipment and hot work (welding/cutting). The developed rehabilitation technique consists of light-weight steel elements and aims to decrease demands to beam-ends of steel moment-resisting frames. The behavior of the baseline model was verified through numerical analysis and proof-of-concept testing. Furthermore, the effectiveness of rehabilitation is studied through retrofitting a four-story steel momentresisting frame originally designed with Japanese design guidelines.
\end{abstract}

KEYWORDS: seismic rehabilitation; minimal-disturbance; steel moment-resisting frames; light-weight elements; tension-only

\section{INTRODUCTION}

A considerable number of existing buildings in earthquake-affected regions are still at risk of poor performance in seismic events. Major earthquakes have shown that older buildings can present serious hazards. Such buildings will still be a part of the landscape throughout the world in the foreseeable future [Nakashima et al, 2014]. Retrofitting at-risk buildings would minimize damage to them and thus decrease the initial disruption to normal functionality. As a consequence, quick recovery would be facilitated, requiring less effort and resources.

Many rehabilitation techniques have been developed and practical applications for the repair and rehabilitation of earthquake-damaged and seismically deficient buildings have been published [e.g., FEMA, 2007; MEXT, 2008, ASCE, 2006]. However, most seismic rehabilitation schemes require significant changes in architectural planning and relocation of occupants during construction. These consequences of retrofitting may be particularly undesirable for many applications. For cases that require relatively small or partial seismic upgrading, rapidly deployable rehabilitation devices may be a preferable option for reducing indirect costs associated with construction. Kurata et al. presented a strategy named rapid seismic rehabilitation and the benefits of adopting a tension-only approach [Kurata et al., 2012a and 2012b]. The benefits of the tension-only system include: (1) elimination of 
undesirable global and local buckling in supplemental load-carrying elements, enabling the use of light-weight steel components; (2) rational implementation of a strict capacity design (over-strength is known or capped); (3) use of simple connections with rapid and adjustable installation.

Deformation capacity of steel moment-resisting frames, designed to achieve a beam collapse mechanism by providing columns with sufficient reserved strength, is controlled primarily by the failure of beam-column connections. When steel beams are connected to a floor slab in such a way that they act as one element, the contributions of the concrete floor slab to the beam are non-negligible. Experience and laboratory testing indicated the major contributions are an increase in flexural strength when the slab is in compression (i.e., positive bending), an increase in the second-moment of inertia of the beam in the strong axis, and asymmetric cyclic deterioration in strength and stiffness [e.g., Leon et al, 1998; Chen and Chao, 2001; Kim et al, 2004; Nakashima et al, 2005]. A full-scale test of a two-story composite steel building with steel moment-resisting frames [Nakashima et al, 2005] demonstrated that the beam flexural strength increased about 1.5 times in positive bending and 1.2-1.4 times in negative bending compared with that of the bare steel beam. However, large tensile strains at the bottom flanges of composite steel beam with concrete slab initiate fracture near column surfaces when subjected to positive bending that puts tension on the lower fibers. In other words, because of composite action, beam-column connections possess reserved deformation capacity to fracture under negative bending relative to positive bending.

Several techniques have been proposed to enhance the ductility of beam-column connections in response to the severe damage observed in the 1994 Kobe and 1995 Northridge earthquakes [Suita et al., 2000; AISC, 2009]. One straightforward method is to strengthen a beam end near the column surface by welding steel plates to increase the area of the bottom flange, shifting the neutral axis in the critical section closer to the mid-height. Another effective method is to intentionally reduce the flange width at the section away from the beam ends (i.e., reduced beam sections) [FEMA, 2008]. However, all these methods require interruption of normal building operations.

This paper presents an innovative rehabilitation technique of steel beam-column connections developed within a design scheme termed minimal-disturbance seismic rehabilitation. The goal of this strategy is improved seismic performance with minimal obstruction of the visual and physical space for building users. The presented rehabilitation technique increases the strength and stiffness of steel beam-column connections and provides stable energy dissipation while reducing the bending-moment demand at beam ends. Contrary to rehabilitation using large structural elements, enhancement by means of the combined multiple seismic measures (e.g., strength, stiffness, added damping and ductility capacity) is expected so as to avoid excessive increase in force demands on the neighboring components and foundations. Disturbance to the original framing is minimized by limiting the location of added elements to the upper part of the frames and thus retaining walking access and sightlines for the building users. First, the design concept and mechanism of the proposed rehabilitation technique are introduced. The behavior and performance are then verified through finite element (FE) analyses and quasi-static loading tests. Finally, the effectiveness of the technique is evaluated through the application to a four-story steel moment-resisting frame. The responses of the bare and rehabilitated frames to a set of ground motions are compared in terms of plastic rotations at beam-ends as well as roof drifts. 


\section{DESIGN CONCEPT}

\subsection{Minimal Disturbance Seismic Rehabilitation for Steel Moment-Resisting Frames}

In steel moment-resisting frames, bottom flanges of composite beam near column surfaces are the location where fracture initiates because of large bending and composite action. The section's neutral axis under positive bending is located at a higher position than that under negative bending because of the large compressive force in the concrete slab. Thus, the fracture normally initiates from the beam bottom flanges rather than from the top flanges, and the deformation capacity before fracture is larger in negative bending than in positive bending. This is true if proper lateral bracing is provided to prevent global buckling after the onset of local buckling at the beam flanges.

Reducing the positive bending moment at the beam ends can enhance the deformation capacity of beam-column connections and eventually that of the overall frame. Such rehabilitation can be achieved by adding supplemental load-resisting components to create alternative load paths in the original frames as shown in Figure 1. This rehabilitation technique, named the Minimal-Disturbance Arm Damper (MDAD), is specifically designed to minimize the disturbance to the existing frame. The use of light steel members enables the installation of the damper without welding or using heavy construction equipment, and the configuration only uses the corner part of the opening, retaining visibility. MDAD connects the mid-span of the beam with the upper part of the column using two identical tension-only rods. Energy dissipation is hysteretic, composed of yielding in steel bending plates at the column-MDAD interface. The plates are attached to the column by post-tension rods. By yielding, the steel plates limit the load exerted on the existing frame under severe earthquakes and dissipate seismic energy in a stable manner without the pinching behavior described in the next section.

The bending plates are connected to the column as shown in Figure 1(b). Bending plates are placed on either side of the column with supported by two spacer plates at their ends. The spacer plates are firmly attached to the column surface by tightening the post-tension rods to cause a large friction force between the plates and the column, preventing the entire MDAD from sliding against the column during loading. These spacer plates ensure that the bending plates do not touch the column, which would stop bending plate deformation, limiting the

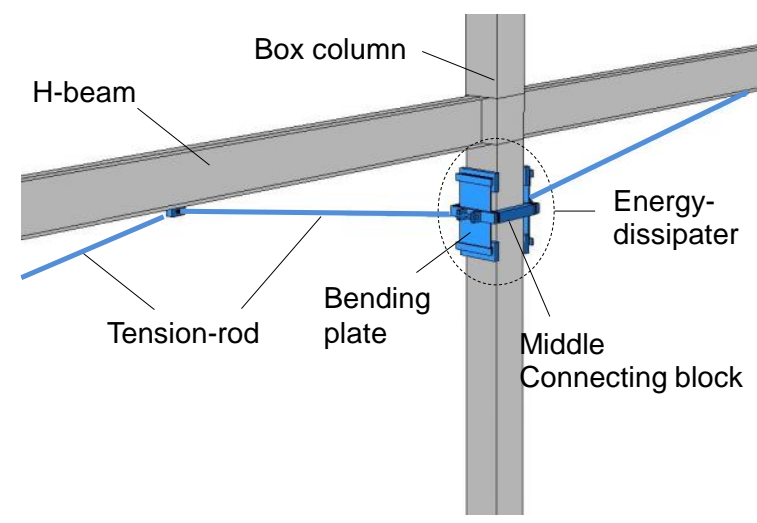

(a)

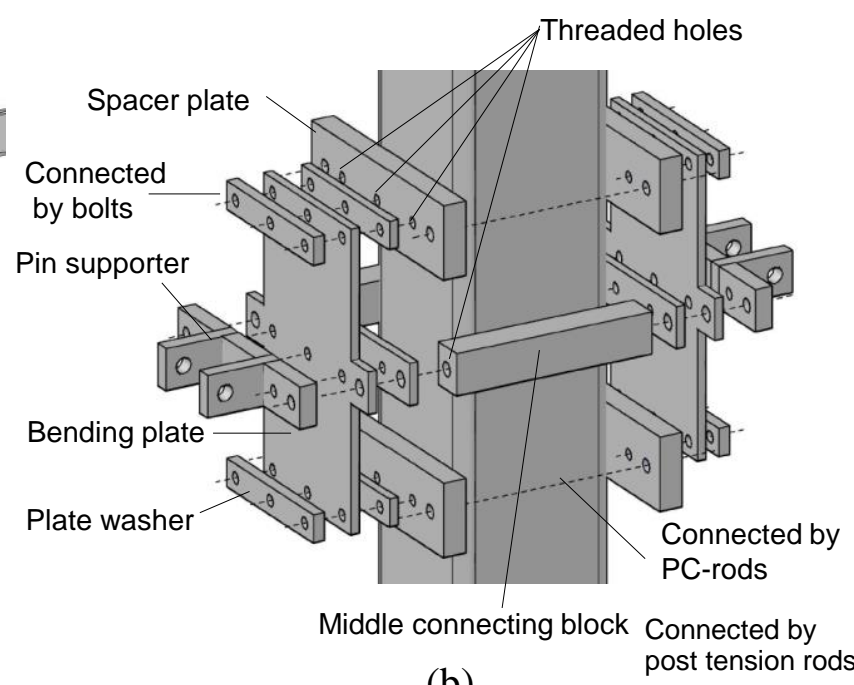

(b)

Figure 1. Schematic of rehabilitation system: (a) overall shape; (b) exploded view of MDAD. 
energy dissipation. The bending plates are fixed to the spacer plates by several bolts. The two rigid rectangular bars named "middle-connecting blocks" connect the two bending plates, so they displace as one. The pin-connection for the tension-rod is bolted to the middle of the bending plate. The other end of the tension-rod is connected to the beam by high-strength bolts which require drilling holes in the beam flanges; there exists a room for future development for this part.

\subsection{Basic Mechanism}

For the MDAD a tension-only load-resisting mechanism was adopted. Figure 2 shows the hysteretic behavior of the MDAD. When the lateral load is applied to a beam-column connection, as shown in Figure 2(a), one side of the beam-column connection opens and the other side closes. Accordingly, the tension-rod in the opening side pulls on the bending plate it is attached to. As the two steel plates are connected at their mid-section, they deform together and yield (point $b$ in Figure 2). The deformation of the steel plates prevents compression of the tension-rod in the closing side. When loading is reversed (Figure 2(b)), at point $\mathrm{d}$ in the hysteresis loop, the tension-rod on the left side starts to sustain tension force, while the tension-rod on the right side loses tension force. Eventually, once the force is great enough on the left tension-rod, the bending plates will yield in the opposite direction. The rod in the compression side does not contract or buckle because of the unique deformation of the pair of bending plates moving together, which results in the generation of a fat loop from point $d$ to e (Figure 2(c)). This mechanism enables the MDAD to dissipate energy with a stable bilinear relationship.

The benefit of reducing the positive bending moment at beam ends, and thus postponing yielding, is illustrated in Figure 3. The tension-rod applies vertical and lateral forces to the beam at mid-span, as well as a bending moment, because of the vertical distance between the point of application of the forces and the beam centroid. These forces and bending moment

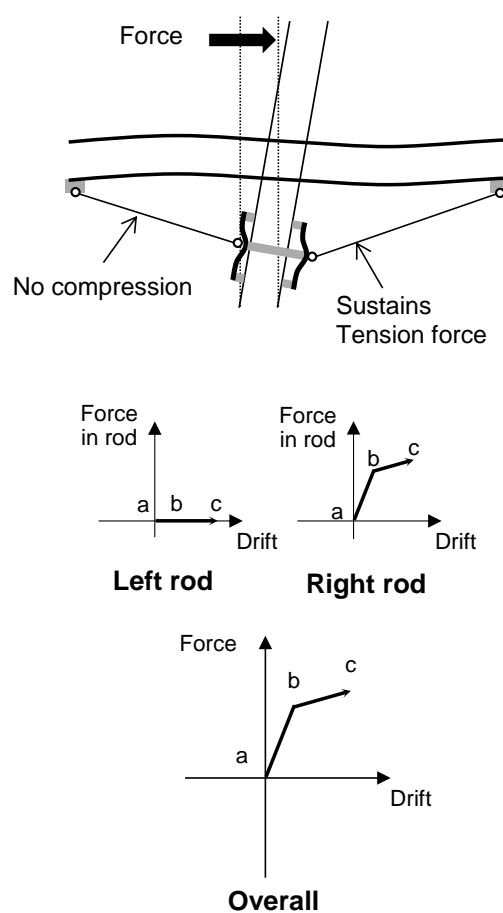

(a)
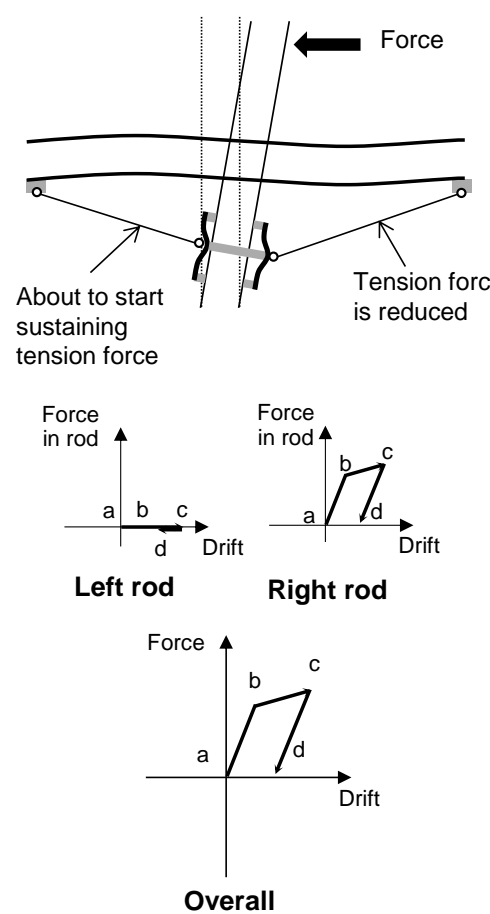

(b)

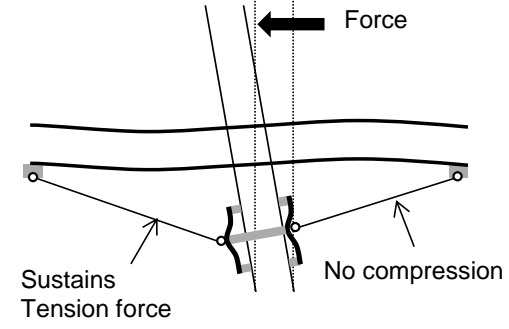

Tension force

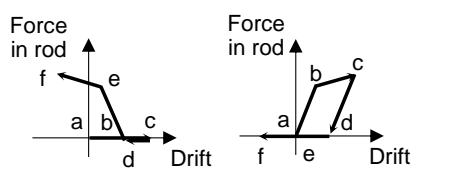

Left rod Right rod

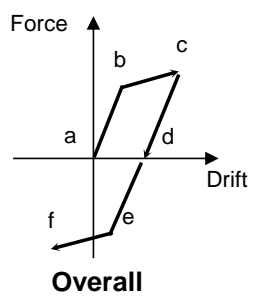

(c)

Figure 2. Mechanism of MDAD: (a) at loading; (b) at unloading; and (c) at reversed loading. 


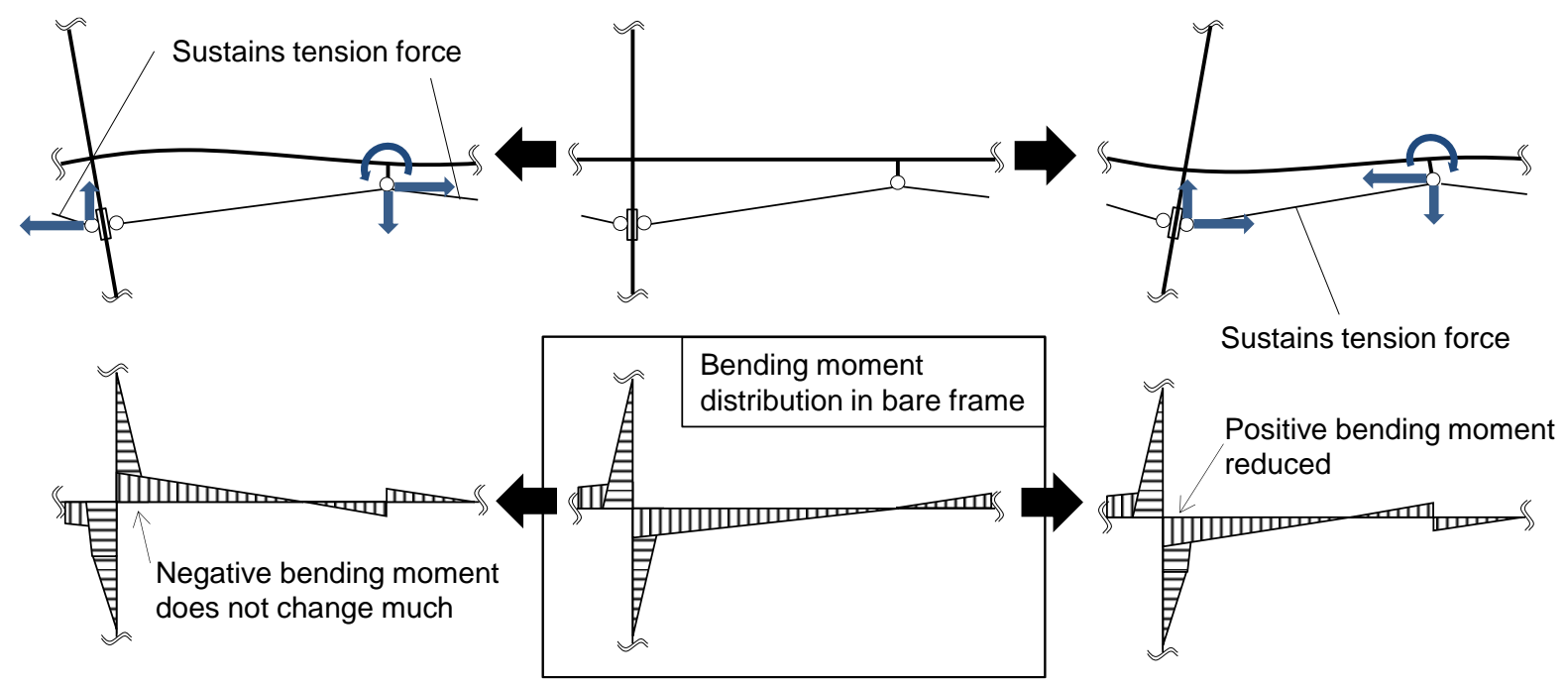

Figure 3. Reduction in demand to beam ends.

generate additive negative bending moment at the beam end that was originally subjected to a positive bending moment. The other beam end that was originally subjected to a negative bending moment sustains little change. For a static pushover loading, the MDAD does not have specific contributions in reducing joint rotation after the yielding of the beam ends. However, the reduction in bending moment while the beam ends remain elastic delays the yielding of the beam ends, and the plastic rotation starts accumulating at a later stage. Thus, even after yielding, for the same drift the plastic rotation is smaller with the MDAD. For earthquake loadings, the MDAD repeatedly delays the yielding of the beam end under positive bending while decreasing story drift by dissipating energy and increasing story stiffness and strength. The MDAD restrains the local deformations of a critical section and enhances the deformation capacity of entire frame in a comprehensive manner.

Similar load-resisting systems using the tension-only approach have been proposed in the past [Pall, 1983; Anagnostides et al., 1989; Mualla and Bellev, 2002; Kurata et al., 2012a; Kang and Tagawa, 2013]. Nevertheless, all of them occupy large spaces because they are configured in $\mathrm{X}$ - or V-bracing. In addition, in the proposed system the size of the energy dissipating part is reduced as much as possible by the positive use of the existing column.

\section{NUMERICAL ANALYSIS}

A baseline model of the MDAD designed for rehabilitating a steel beam-column connection in a low-rise steel moment-resisting frame was numerically analyzed using general-purpose FE analysis code. The load-resisting and energy-dissipating mechanism of the MDAD was verified and the design details of the baseline model were examined.

\subsection{Baseline model}

The baseline model of the MDAD was designed for a frame with a $7.2 \mathrm{~m}$ span and $3.6 \mathrm{~m}$ story height, representative of typical low-rise steel moment-resisting frames in Japan. The beam and column sections were selected as H-400 $\times 200 \times 9 \times 16\left(Z_{p x}=1.56 \times 10^{6} \mathrm{~mm}^{3}\right)$ and HSS$350 \times 350 \times 19\left(Z_{p}=2.97 \times 10^{6} \mathrm{~mm}^{3}\right)$ from Japanese standard sections. The design yield strength of the MDAD in terms of lateral-resisting force was tentatively set at around $10 \%$ of the shear strength of the column. The stiffness of the MDAD was selected to yield at a story drift of 
$1.0 \%$. The design yield strength of the MDAD in terms of lateral-resisting force was tentatively set at around $10 \%$ of the shear strength of the column. The stiffness of the MDAD was selected to yield at a story drift of $1.0 \%$. The MDAD was located at three quarters of the story height, considering the balance between the minimal disturbance to the users' eyesight and the effectiveness of MDAD. With this configuration, the strength and stiffness of the MDAD can be easily controlled by adjusting the dimension of bending plates. The aforementioned designed requirements were achieved with a reasonable dimension of bending plates (length $\times$ width $\times$ thickness $=450 \mathrm{~mm} \times 350 \mathrm{~mm} \times 19 \mathrm{~mm}$ ) and tension rods with a diameter of $45 \mathrm{~mm}$.

\subsection{Behaviors in Finite Element Simulations}

The basic behavior of the baseline MDAD model was examined using a simplified model as illustrated in Figure 4(a). This model is built to a half scale to estimate the responses of following experimental tests conducted in a half scale. In this model, only the MDAD resisted the lateral-force that was applied at the bottom of the column, and the flexibility of columns and beams was not included. As the MDAD only adds axial force less than $10 \%$ to the yielding axial force of beams, undesirable deformation at beam-column connections or reduction in bending moment capacity due to the added axial force is not expected. The fundamental behavior of this model was examined using FE analysis code, Abaqus [Dassault Systems, 2010]. The model consisted of a pin-supported column and the MDAD as shown in Figure 4(b). The column was modeled as being elastic using shell elements (4-node quadrilateral shell element with reduced integration). The energy-dissipating part of the MDAD, consisting of steel bending plates, spacers and a middle connecting block (see Figure 1 for details), was modeled using solid elements (3D 8-node linear isoparametric element with reduced integration). The spacers were rigidly attached to the column surface and thus no slippage at the surface was allowed. The tension-rods were modeled using a beam element (B31) with moment release at both ends. The steel bending plates had a bilinear stress-strain relationship with a yielding stress of $300 \mathrm{MPa}$ and strain hardening of $0.5 \%$. To trace the plasticity in the plates accurately, they were finely meshed with six elements along the thickness. Figure 4(c) shows a close-up of the energy dissipater of the MDAD during cyclic loading. Two bending plates pulled by the tension-rod deformed together as intended in the design. The space between the bending plates and the column flange was sized based on a preliminary finite element analysis, and thus the touching between the plates and column does not occur even under very large deformations.

Figure 4(d) shows the force-deformation relationship of the baseline MDAD model under incremental cyclic loading. The loading was controlled with beam-column rotation that was computed using the displacement of the column at the mid-location of the energy dissipater. The loading was repeated for two cycles at amplitudes of $1 \%, 2 \%$, and $3 \%$. The resulting hysteresis behavior was a stable and "fat" loop. The steel bending plates yielded at a beamcolumn rotation of $0.8 \%$ and a lateral force of $15 \mathrm{kN}$. The lateral force reached $23 \mathrm{kN}$ by the end of the loading. Figure 4(e) shows the force history of the tension-rods in terms of the beam-column rotation. Over the entire loading, one of the tension rods always carried a force while a slight gap appeared at zero force during a transfer of force from one tension-rod to the other. The rod force was $52 \mathrm{kN}$ at the yielding of the steel bending plates and $105 \mathrm{kN}$ at the end of loading. These values were below the yield strength of the tension-rods, which was $132 \mathrm{kN}$. 


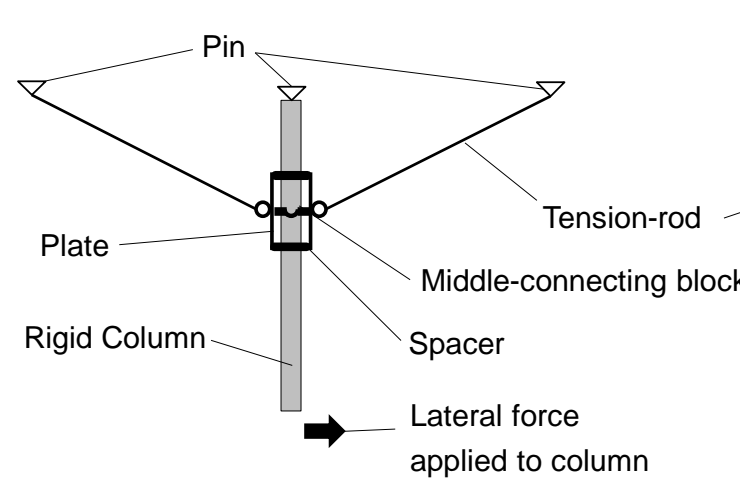

(a)
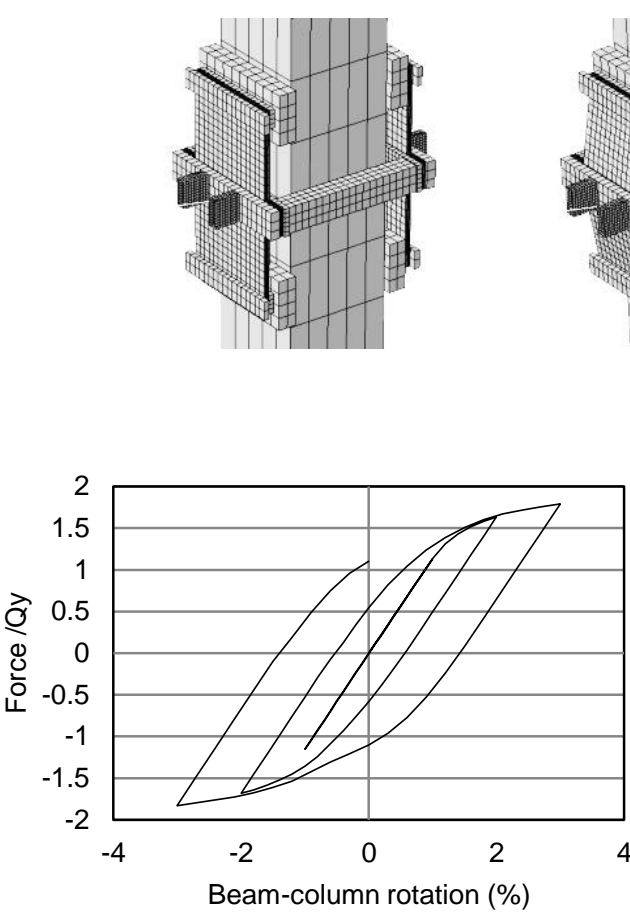

(d)
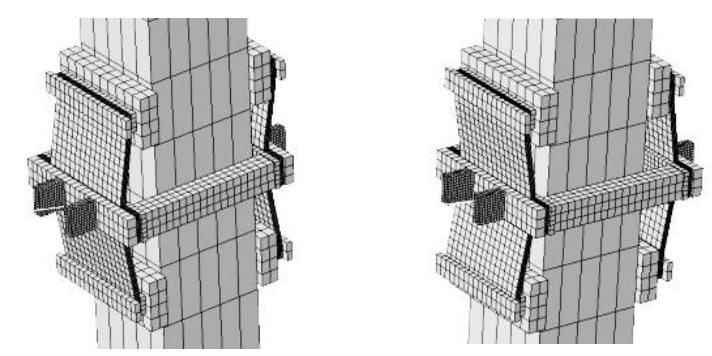

(c)

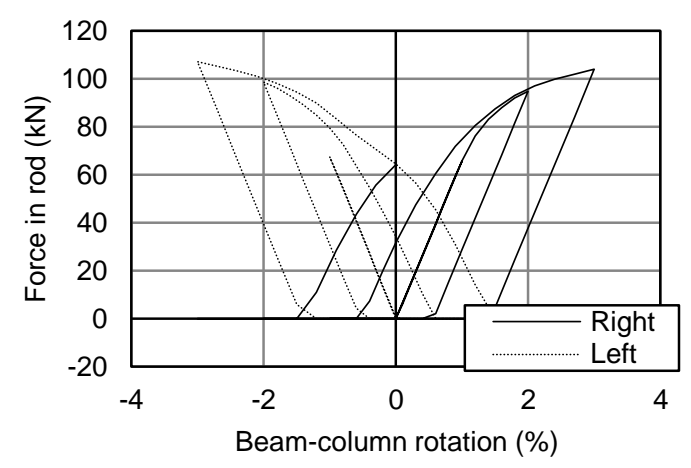

(e)

Figure 4. Numerical simulation of baseline model: (a) explanation of simplified model; (b) FE model; (c) behavior of bending plates in FE analysis; (d) relationship between lateral force and beam-column rotation; (e) force history in tension-rod.

\section{EXPERIMENTAL PROGRAM}


The basic behavior of the baseline model was first examined using a setup examining only the behavior of the MDAD, without considering the flexibility of the steel beam-column connection to be rehabilitated. Afterwards, a steel beam-column connection rehabilitated with the MDAD was tested.

\subsection{Test Specimens}

To examine the behavior of the rehabilitation technique in detail, four parameters were considered: the rigidity of the middle connection block, the location of the bending plates, the force in the post-tension rods, and the steel yield strength. Table 1 shows a summary of the specimens. Specimen 1 was regarded as the baseline model that was analyzed at half scale in Section 3.2. Specimen 2 used relatively flexible elements for the middle connecting block, i.e., 4.3 times less in axial stiffness, and thus the two bending plates attached to the column were expected to deform differently. In Specimen 3, the effect of the inclined angle of the tension rods on the behavior was examined by attaching the bending plates slightly farther from the beam-column joint node, i.e., at $600 \mathrm{~mm}$ in Specimen 3 instead of $400 \mathrm{~mm}$ in Specimen 1. In Specimen 4, the force in the post-tension rods was increased from $30 \mathrm{kN}$ to $50 \mathrm{kN}$ to prevent the slippage of the bending plate on the surface of the column. In Specimen 5, low-yield-point (LYP) steel that is characterized by low yielding stress and significant isotropic strain hardening was used for the bending plates to achieve yielding and energy dissipation at small levels of deformation. In Specimen 6, two plates made of high-strength steel (HS) and LYP were stacked and jointed by bolts at the middle and both ends. This configuration was intended to achieve early yielding while maintaining a large secondary stiffness. Finally, Specimen 1 was applied to a beam-column connection.

The shape of the bending plates in the various specimens differed slightly [Figure 5]. Specimens 1, 3, 4 and 5 used bending plates with wings in the middle, and the stiffness in the connecting region to the middle connecting blocks was increased. Specimen 2 used the bending plates without wings and thus had relatively small out-of-plane flexibility at the connections to the middle connecting blocks. Specimen 6 used the bending plates made of HS and LYP with different plate widths.

\subsection{Test Setup}

The performance of the proposed system was evaluated through a series of quasi-static cyclic loading tests. Figure 6(a) shows the loading system for the component tests. The test setup for the component level test consisted of an elastic column and two short beams that represented the mid-part of the beams. The column bottom was pin-connected so that only the rehabilitation system resisted the lateral force applied at the top of column by a hydraulic jack. The column was $1913 \mathrm{~mm}$ long and the distance between the centers of the two short beams was $3600 \mathrm{~mm}$. The typical assembly of the proposed system was as follows: 1) steel bending plates were firmly attached to the surfaces of column over spacers using post-tension rods with a force of $40 \mathrm{kN} ; 2$ ) the mid-sections of two steel bending plates placed at the two sides of the column were connected to each other using a rigid steel block; 3) the mid-span of beams and the mid-sections of the steel bending plates were connected with tension-rods and tightened with turnbuckles.

Figure 6(b) shows the test setup for an application test, in which a beam-column connection with a story height of $1800 \mathrm{~mm}$ and beam span of $3600 \mathrm{~mm}$ was rehabilitated with the proposed system. The column base was pin-connected and the beam ends were roller- 
Table 1. Test specimens for component tests

\begin{tabular}{|c|c|c|c|c|c|c|}
\hline Sp. & Steel type & $\begin{array}{c}\text { Plate location } \\
{[\mathrm{mm}]}\end{array}$ & $\begin{array}{c}\text { Plate width } \\
{[\mathrm{mm}]}\end{array}$ & $\begin{array}{c}\text { Thickness } \\
{[\mathrm{mm}]}\end{array}$ & $\begin{array}{c}\text { Force in } \\
\text { post-tension } \\
\text { rod }[\mathrm{kN}]\end{array}$ & $\begin{array}{c}\text { Connector } \\
\text { between } \\
\text { plates }\end{array}$ \\
\hline 1 & SS400 & 400 & 175 & 9 & 35 & Block \\
\hline 2 & SS400 & 400 & 175 & 9 & 35 & $\begin{array}{c}\text { Post-tension } \\
\text { rod }\end{array}$ \\
\hline 3 & SS400 & 600 & 175 & 9 & 35 & Block \\
\hline 4 & SS400 & 400 & 175 & 9 & 50 & Block \\
\hline 5 & LYP & 400 & 175 & 9 & 35 & Block \\
\hline 6 & HS/LYP & 400 & $100 / 150$ & $6 / 9$ & 35 & Block \\
\hline
\end{tabular}

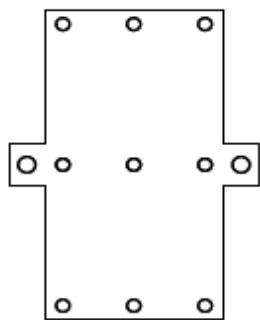

(a)

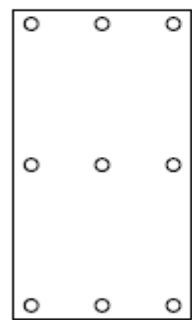

(b)

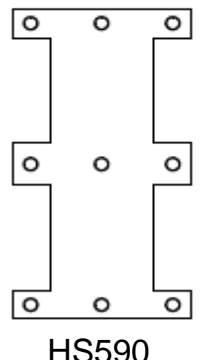

(c)

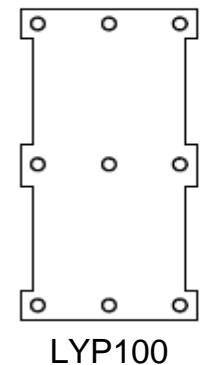

)

Figure 5. Shape of bending plates: (a) Specimen 1 and 3-5; (b) Specimen 2; (c) Specimen 6.

supported. The top of column was connected to a hydraulic jack. The sizes of the main components were: (a) a HSS column with a $\square-175 \times 175 \times 12$ cross-section; (b) beams with a H$200 \times 100 \times 5.5 \times 8$ cross-section; (c) M22 tension rods.

\subsection{Measurement system}

The locations of the displacement transducers (DT) and strain gauges (S) are shown in Figure 6(a) and (c). In both tests, the displacement of the loading point was recorded using DT1. In the component tests, the column displacement for computing the beam rotation angle was measured as the average displacement from DT5 and DT6. DT2 and DT3 monitored the horizontal deformation of the pins. In the application test, the horizontal displacement of the beam-ends was measured using DT9 and DT10. In both tests, DT7 and DT8 monitored the vertical slippage of steel bending plates against the column.

The axial forces in the tension-rods were monitored using S1 and S2 attached to the turnbuckles, which were the part of the tension-rod. S3 and S5 were used to monitor the force in the post-tension rods. S4 was used to monitor the axial force in the middle connecting block. When the beam was added to the setup (Figure 6(c)), S6 to S9 were used to estimate the bending moments in the beam.

\subsection{Loading protocol}

The loading protocols used in the tests are shown in Figure 7. Loading was repeated three times at displacements under $1 \%$ drift and twice for larger amplitudes. For the component test, the loading protocol was applied as a beam-column rotation that was computed using the displacement of the column at the mid-location of the energy dissipater. The amplitude of the rotation angle was increased from $0.25 \%$ to $3 \%$. In Specimens 3 and 4 with steel bending 

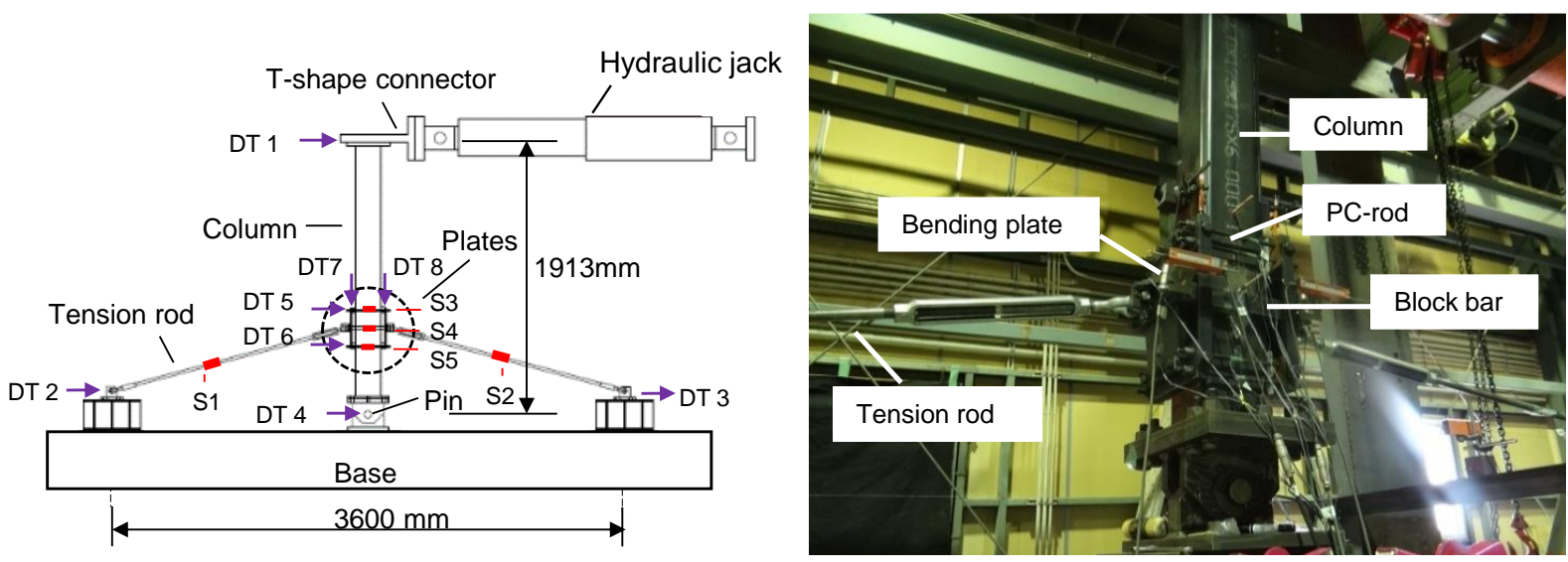

(a)
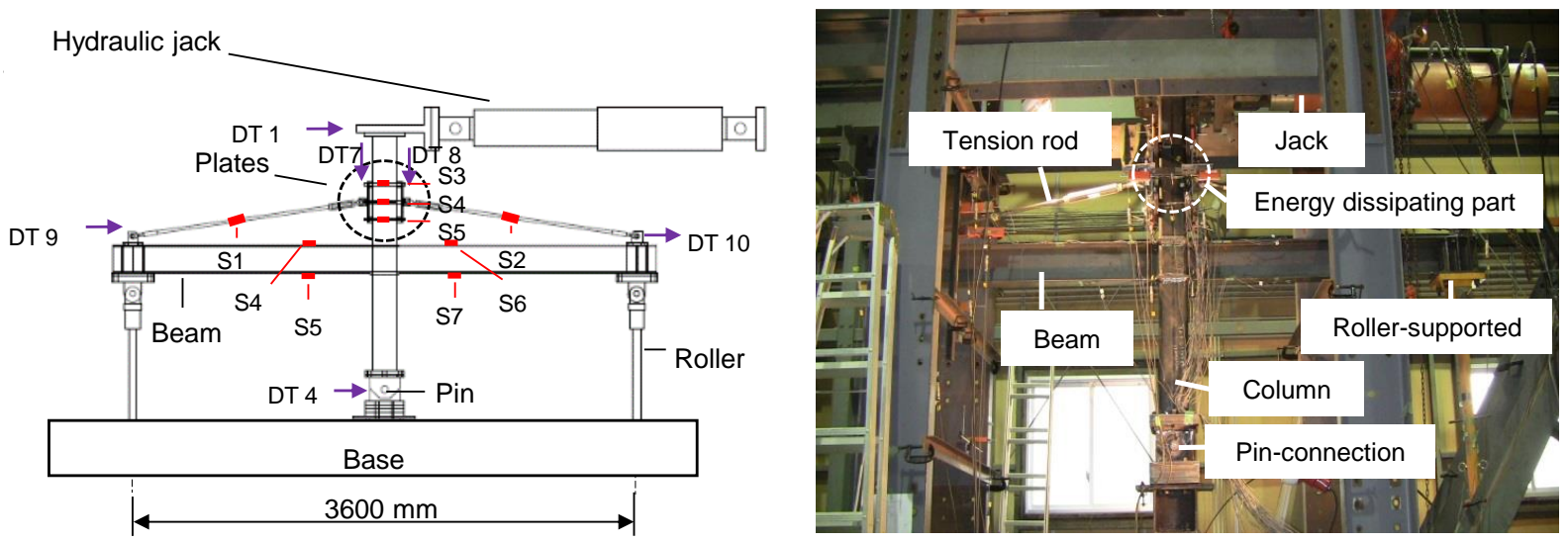

(b)

Figure 6. Loading system and measurement plan: (a) component test; (b) photo of component test setup; (c) application test; (d) photograph of application test setup.

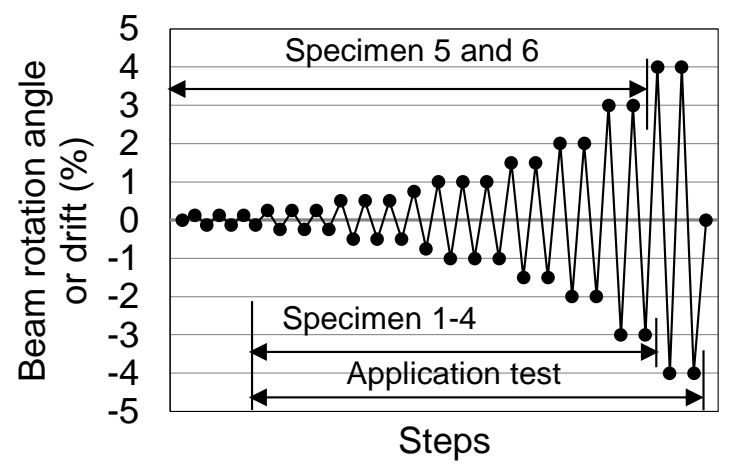

Figure 7. Loading protocol.

plates made of LY100, three cycles of $0.125 \%$ loading were added to examine the early yielding of the bending plates. For the application test, the loading protocol was applied as story drift that was calculated as the column top displacement divided by the story height. The loading continued until $4 \%$, taking into account the extra deformation resulting from the flexibility in the beam-column connection. 
Table 2 Material properties

\begin{tabular}{|c|c|c|c|c|c|c}
\hline \multirow{2}{*}{$\begin{array}{c}\text { Material } \\
\text { properties }\end{array}$} & \multicolumn{3}{|c|}{ Steel plates } & Beam flange & Beam web & Tension-rod \\
\cline { 2 - 7 } & SS400 & LY100 & HS590 & SS400 & SS400 & SS400 \\
\hline $\begin{array}{c}\text { Yield stress } \sigma_{\mathrm{y}} \\
\left(\mathrm{N} / \mathrm{mm}^{2}\right)\end{array}$ & 290 & 58 & 550 & 326 & 335 & 350 \\
\hline $\begin{array}{c}\text { Maximum } \\
\text { stress } \sigma_{u} \\
\left(\mathrm{~N} / \mathrm{mm}^{2}\right)\end{array}$ & 440 & 239 & 655 & 448 & 455 & 548 \\
\hline
\end{tabular}

Three different steel materials, conventional mild steel (SS400), LY100 and high strength steel (HS590) were used in the tests. Their material properties obtained from coupon tests are shown in Table 2. For the application test, the material properties of the beam flange and web were also obtained.

\section{TEST RESULTS}

The results for the component tests and the application test are summarized and compared with the results of the preliminary analysis in Figures 8 to 11. In the plots, the solid and the dotted lines correspond to the test and analysis results, respectively.

\subsection{Baseline Model}

Figure 8(a) shows the overall behavior of the baseline specimen. The tests behaved well with stable energy dissipation up to large deformations. The initial stiffness matched well between the test and analysis, with a discrepancy less than $10 \%$. The drift at yielding was $0.95 \%$ in the test and $1.15 \%$ in the analysis. The strength at the yielding of the bending plates was $16.0 \mathrm{kN}$ in the test and $17.0 \mathrm{kN}$ in the analysis. The maximum strength at a $3 \%$ beam-column rotation was $23.4 \mathrm{kN}$ in the test and $23.3 \mathrm{kN}$ in the analysis. As intended in the design, the two bending plates connected by the rigid middle-connection block deformed together, i.e., when one went towards the column, the other moved away from the column (Figure 9). Thus, the tension rods only sustained tension forces (Figure 8(b)) and no contraction or buckling was observed as a result of the innovative geometric configuration. The maximum force in the tension rods was $102 \mathrm{kN}$, sufficiently below their yielding strength. However, a pinching behavior, defined as the shift of beam-column rotation over $0.1 \%$ near the zero force in the hysteresis loop, became obvious at the second cycle of $1.5 \%$ drift. The shift of beam-column rotation due to the pinching was $0.15 \%$ in this cycle. This was caused by the vertical slippage of the bending plates against the surface of the column. When the bending plates slipped, the distance between the two ends of the tension-rod was shortened, generating the pinching seen in the relationship between the force and beam-column rotation. This phenomenon was also seen in Figure 8(b) as gaps in the deformation at the transition of force from one tension-rod to the other. The slipping of the bending plates was caused by uneven contact between the spacers and the column because of the shape of the box-column section where the midsurfaces were slightly recessed at the corners. This caused the friction force at the spacercolumn interface to be lower than anticipated. Measures to overcome such slippage through enhanced friction force were later developed. 
The horizontal dotted line in the figure corresponds to the design strength of the basic model. The design strength was defined as the yielding of the full plate section and computed using the following equation:

$$
Q_{y}=\frac{4 b_{p} t_{p}^{2}}{l_{p}} \sigma_{y p} \times \frac{d}{L_{c}}
$$

$Q_{y}$ indicates the force at the bottom of the column at the yielding strength of the plates, $b_{p}$ the width of the plates, $t_{p}$ thickness of the plates, $l_{p}$ vertical length of the plates, $\sigma_{y p}$ yielding stress of the plates, $d$ the distance between the beam-column connection and the bending plates, and $L_{c}$ the length of the column. The ultimate strength of the MDAD $Q_{u}$ is approximately $1.5 Q_{y}$ for plate bending. For instance, the maximum strength of the baseline specimen calculated as Eq. 1 multiplied by 1.5 was about $23 \mathrm{kN}$, which was consistent with the test results. Note that the proposed equation is not applicable to the MDAD with LYP plates of large strain hardening.

\subsection{Alternate configurations}

The hysteresis behavior of Specimens 2-6 are shown in Figure 10. Lateral forces in the plots for Specimens 1-4 are normalized according to their design strength computed using Eq. 1. In Specimen 2, the two plates were connected by the flexible bars at their middle. The elongation of the middle-connecting bar was 10 times greater than that in Specimen 1 where the plates were connected by the stiff blocks. The deformation of each plate was allowed to be independent, which caused considerable pinching behavior as seen in Figure 10(a). This result implies that the middle-connecting block must be designed to be sufficiently rigid.

In Specimen 3, the bending plates were located farther from the beam-column joint node; the

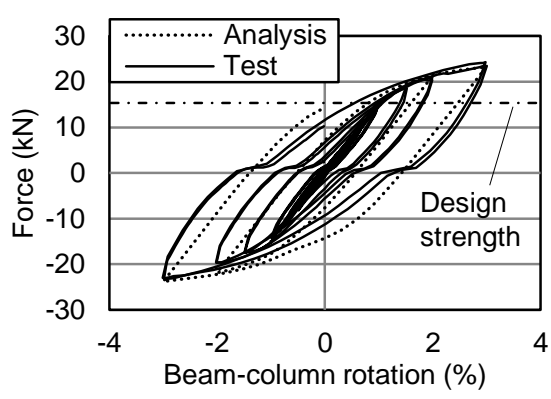

(a)

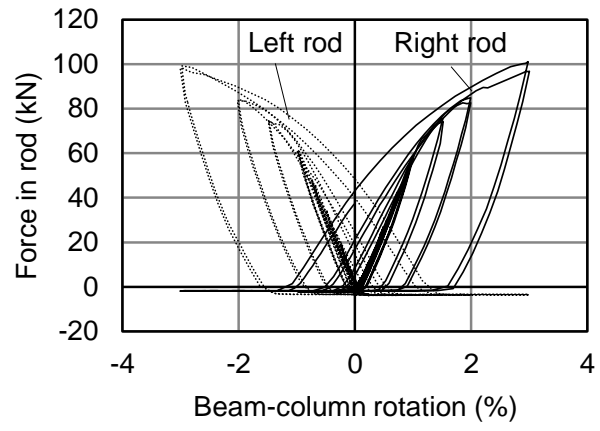

(b)

Figure 8. Baseline model: (a) overall behavior; (b) force history in the tension rods.

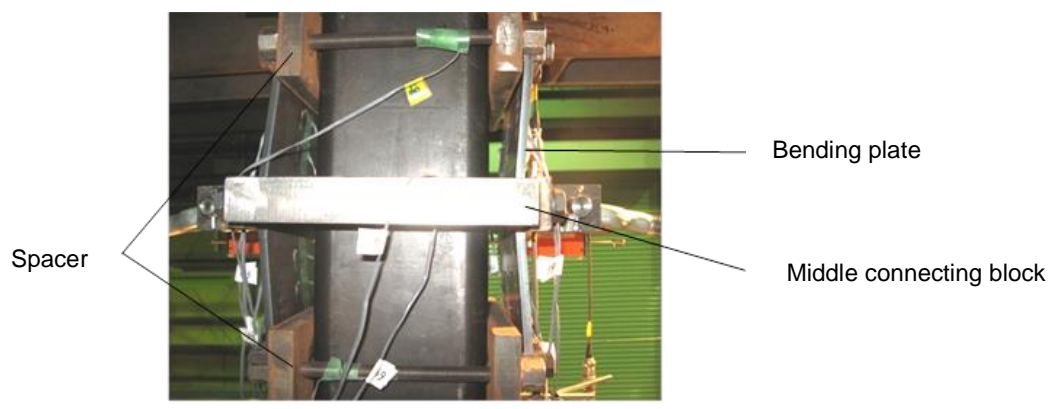

Figure 9. Deformed shape of the bending plates in the baseline model. 
distance was increased from $400 \mathrm{~mm}$ to $600 \mathrm{~mm}$. Because of the larger inclined angle of the tension-rods, the force in the tension-rods increased by 1.5 times from the baseline specimen when compared at the same beam-column rotation. Accordingly, the beam-column rotation at the yielding of the bending plates became less than that in the baseline specimen (Figure 10(b)). Moreover, as the point of the rod force moved farther from the beam-column joint node, the initial stiffness and the yield strength increased by 1.5 times and 2.2 times from the baseline specimen. However, this configuration increased the disturbance to the occupied building area and the pinching behavior increased because of greater slippage caused by increased vertical forces at the column interface.

In Specimen 4, a force 1.6 times that of the baseline model was applied to the post-tension rods that fixed the plates to the column (Figure 10(c)). At 1.5\% beam-column rotation, quite small vertical slippage was observed but no pinching behavior appeared in the hysteresis loop until 3\%. At 3\%, the vertical slippage reached $2 \mathrm{~mm}$ and the pinching behavior at $0.15 \%$ was seen in the hysteresis loop. According to this result, it was revealed that the vertical slippage within $2 \mathrm{~mm}$ did not affect the overall behavior. It was also found that the pinching behavior in the hysteresis loop in Specimens 1 and 3 was caused by this vertical slippage, which reached $5 \mathrm{~mm}$ in these specimens.

In Specimen 5, low yielding steel was used for the bending plates instead of conventional steel (Figure 10(d)). The plates yielded at $0.12 \%$ beam-column rotation. The hysteresis curve showed the stable energy-dissipation capacity with isotropic strain hardening. However, the maximum strength was much less than the baseline specimen because the dimensions of the plates were the same.

In Specimen 6, low-yielding point and high strength steel plates were combined. They were designed to have equal initial stiffness to the baseline specimen (Figure 10(e)). The lowyielding-point steel plates yielded in beam-column rotations as small as $0.17 \%$, meaning that energy dissipation was initiated earlier as in Specimen 5. However, the high strength steel plates remained elastic until 1.5\%, so the maximum strength was higher than Specimen 5 and relatively high secondary stiffness was achieved.

Figure 10(f) shows the energy dissipation capacity calculated according to the definition of the equivalent viscous damping coefficient, $h_{e q}$ [Chopra, 2001]. In Specimen $1, h_{e q}$ was small in the earlier stages of loading but increased gradually after $1 \%$ beam-column rotation when the plates yielded. In Specimen 2, which showed the pinching behavior, $h_{e q}$ was relatively small at 0.1 even in large beam-column rotation such as $2 \%$ to $3 \%$. In Specimen 5 , the low yielding steel started to dissipate energy from $0.12 \%$; consequently, $h_{e q}$ was four times greater compared with the baseline specimen at $1 \%$ drift, and finally achieved 0.3 . Also in Specimen 6, the low yielding steel resulted in larger $h_{e q}$, but not as large as Specimen 5 because of the reduced dimension of the low-yielding-point steel plates in Specimen 6 compared with Specimen 5.

The initial stiffness, yielding strength and maximum strength for the component tests are summarized in Table 3. The results of numerical simulation by FE analysis and the calculated design strengths are also shown in the table. In the test results, yielding strength was defined as the point where the stiffness started to decrease significantly. 


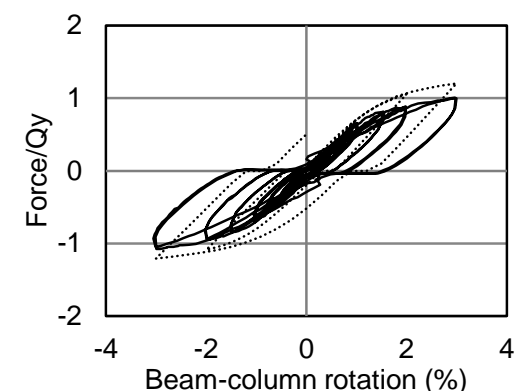

(a)

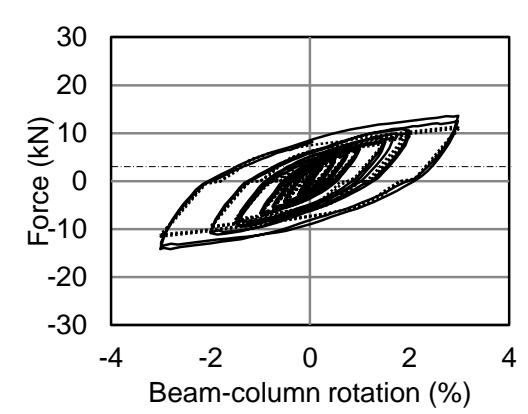

(d)

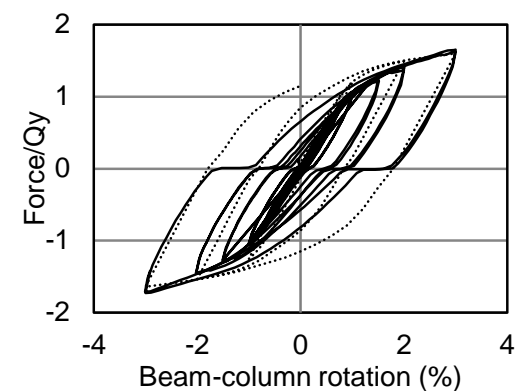

(b)

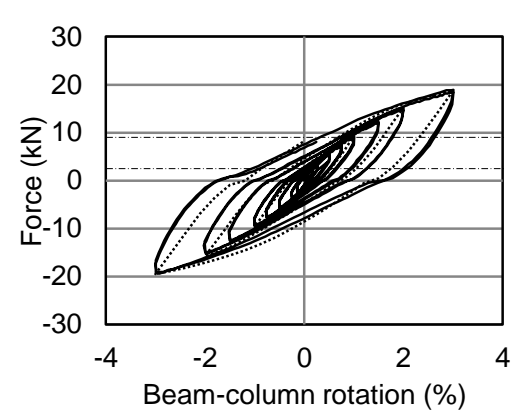

(e)

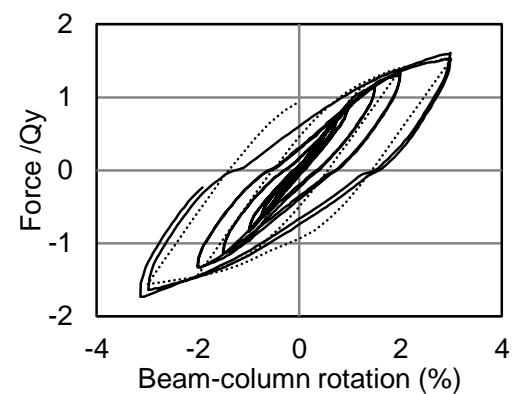

(c)

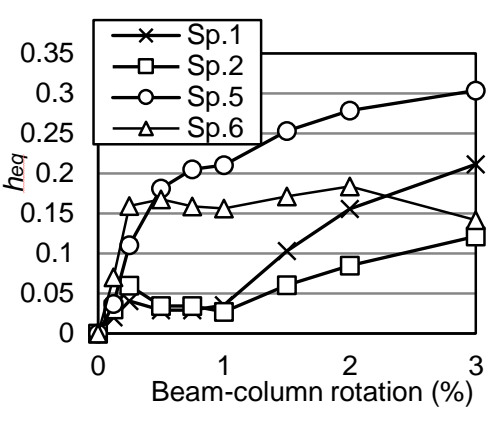

(f)

Figure 10. Component tests: (a) Specimen 2; (b) Specimen 3; (c) Specimen 4; (d) Specimen 5; (e) Specimen 6; (f) energy dissipation capacity.

Table 3. Component tests

\begin{tabular}{|c|c|c|c|c|c|c|c|c|}
\hline \multirow{2}{*}{ Sp. } & \multicolumn{2}{|c|}{$\begin{array}{c}k\left[\times 10^{2} \mathrm{kN} / \mathrm{rad}\right] \\
\text { Initial stiffness }\end{array}$} & \multicolumn{3}{c|}{$\begin{array}{c}Q_{y}[\mathrm{kN}] \\
\text { Yielding strength }\end{array}$} & \multicolumn{3}{c|}{$\begin{array}{c}Q_{u}[\mathrm{kN}] \\
\text { Maximum strength }\end{array}$} \\
\cline { 2 - 9 } & FE analysis & Test & Design & FE analysis & Test & Design & FE analysis & Test \\
\hline 1 & 14.8 & 16.8 & 15.3 & 17.0 & 16.0 & 23.0 & 23.3 & 23.4 \\
\hline 2 & 11.3 & 10.6 & 15.3 & 12.0 & 10.5 & 23.0 & 18.4 & 15.1 \\
\hline 3 & 30.8 & 28.0 & 22.9 & 24.0 & 24.5 & 34.4 & 36.9 & 38.0 \\
\hline 4 & 11.7 & 14.1 & 15.3 & 17.0 & 16.0 & 23.0 & 23.3 & 24.6 \\
\hline 5 & 14.8 & 14.2 & 3.2 & 2.5 & 3.0 & 4.8 & 11.5 & 13.4 \\
\hline 6 & 14.1 & 13.0 & 2.7 & 3.5 & 3.5 & 4.1 & 18.7 & 18.9 \\
\hline
\end{tabular}

443

444

445

446

447

448

449

450

451

452

453

454

455

456

\subsection{Application to Beam-Column Connection Assemblage}

In the application test, the MDAD, which had the same dimensions and material properties as Specimen 1 in the component test, was installed in a beam-column connection. Although in the real application this system was attached below the beams, in the test the specimen was placed upside down for easier installation. Figure 11(a) shows the overall behavior of the rehabilitated frame, and Figure 11(b) shows the comparison between the bare and rehabilitated frames. The lower horizontal line in Figure 11(b) corresponds to the design force when the bending moment at the beam ends of bare frame reaches the plastic moment $\left(F_{p}\right)$ and the upper line corresponds to $F_{p}$ plus the yield strength of the MDAD calculated by Eq. 1 . The results of the test showed that: (1) the MDAD behaved as expected during the deformation of the beam and column; and (2) the initial stiffness and strength at $4 \%$ drift increased by $26.1 \%$ and $27.4 \%$ compared with the non-rehabilitated beam-column connection. 


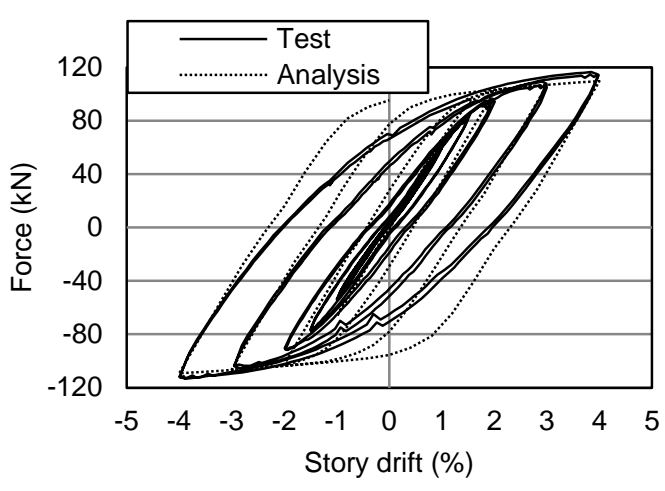

(a)

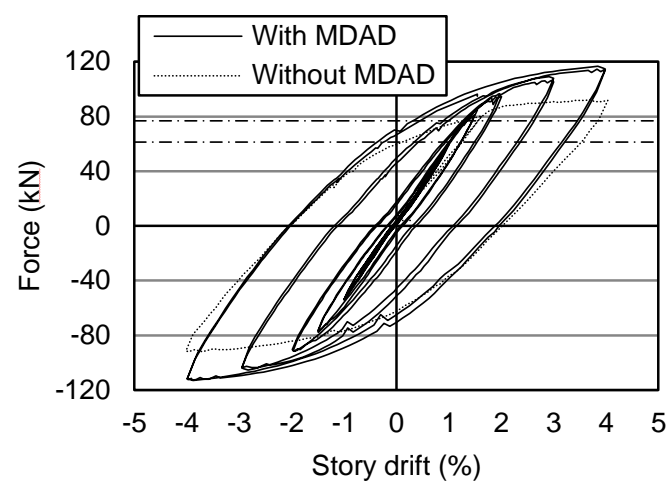

(b)

Figure 11. Application test: (a) force-story drift plot; (b) with and without MDAD.

457

458

459

460

461

462

463

464

465

466

467

468

469

470

471

472

473

474

475

476

477

478

479

480

481

482

483

484

485

486

487

488

489

490

491

492

493

For reference information, attaching the MDAD at a half scale took only 1.5 hours with two workers, and all was implemented by hand without any welding.

\section{FOUR-STORY STEEL MOMENT-RESISTING FRAME}

\subsection{Description of the Bare Frame}

A case study of a four-story building designed in accordance with the requirements for Japanese seismic design was used to investigate the overall effect of the MDAD on the behavior of a frame. The building was a four- by two-bay frame structure (Figure 12(a)). The steel was SS400 with a modulus of elasticity of 205,000 MPa and a yield strength of $235 \mathrm{MPa}$. The dimensions of the beam and column are given in the figure. The floor mass taken by this frame was $302,400 \mathrm{~kg}$, and its fundamental period was $0.78 \mathrm{~s}$. The base shear coefficient of the elastic stage was 0.27. Considering the composite effect with the concrete floor slab, the moment of inertia of beams was increased by 1.8 times in positive bending where the concrete slab sustained a compression force.

For the purpose of analysis, a model of the frame was built and analyzed in OpenSees (Mazzoni, 2009). Concentrated plasticity was assumed for both the beam and column elements, while shear deformations were ignored. The effect of the concrete slab on the composite beam stiffness was determined by adopting an elastic fiber model along the span of the beams while adopting a no tension material model for the concrete slabs. This led to a moment of inertia in positive bending that was 1.8 times that of the bare steel beam. No deterioration in the composite action is considered in the model. Zero length elements with an effectively rigid-plastic moment rotation relationship were adopted to model the plastic hinge behavior at the beam and column ends. The positive and negative yield moments of the composite beam section were taken as 1.3 and 1.0 times the yield moment of the steel beam section, respectively. The value of its post-yielding stiffness was computed such that a secondary stiffness of 0.01 was achieved at the beam level. The chord rotation of composite beams at fracture ranges from $0.02 \mathrm{rad}$ to $0.036 \mathrm{rad}$ according to the references [7]-[11]. In this paper that the chord rotations at fracture were defined as $0.02 \mathrm{rad}$ and $0.03 \mathrm{rad}$ for positive and negative bending, respectively. Accordingly, the plastic hinge rotations at fracture, without elastic beam deflections, were set as $0.015 \mathrm{rad}$ and $0.022 \mathrm{rad}$ for positive and negative bending.

As shown in the next sections, the performance of the bare frame (without the addition of any retrofit method) was not satisfactory. The main performance issue was excessive positive plastic hinge rotations, and thus, application of the MDAD was deemed appropriate. The next 
section describes the MDAD allocation layout and properties. Section 6.3 will then present the pushover curves of the bare and retrofitted frames while Section 6.4 presents their behavior in nonlinear time history analysis under a suite of ground motions.

\subsection{Damper Allocation Layout and Properties}

During pushover analysis of the bare frame, the first two stories exhibited large positive plastic rotations compared with the top stories (not shown). Therefore, the retrofitting scheme employed MDADs with similar properties in the first two stories (see Figure 12(b)). The MDADs are also installed on exterior columns with the intention of reducing the positive bending moments at the beam ends. The MDADs applied to the exterior columns have a typical ratcheting behavior rather than a hysteretic behavior, characterized by stable "fat" loops. Nonetheless, the forces they produce at a maximum drift assist in reducing the positive bending moments and delay yielding and fracture.

The MDADs were designed to yield at a force of $330 \mathrm{kN}$ and a drift of $0.36 \%$. The force was designed as MDADs reduced the positive bending moment at the beam end to $60 \%$ or the original value examined at the yielding drift of the bare frame. The stiffness of MDADs was adjusted to achieve $35 \%$ earlier yielding of the bending plates compared with the beam ends

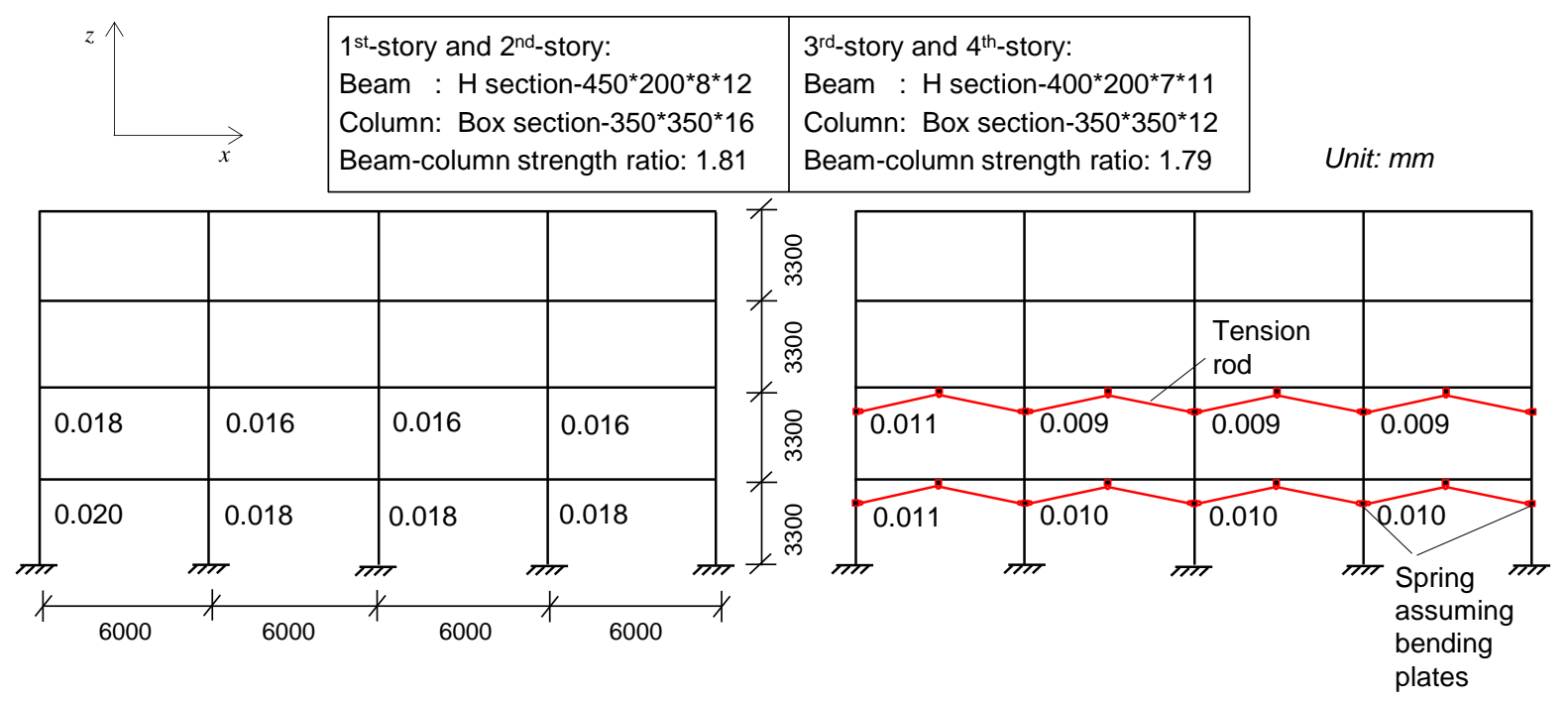

(a)

(b)

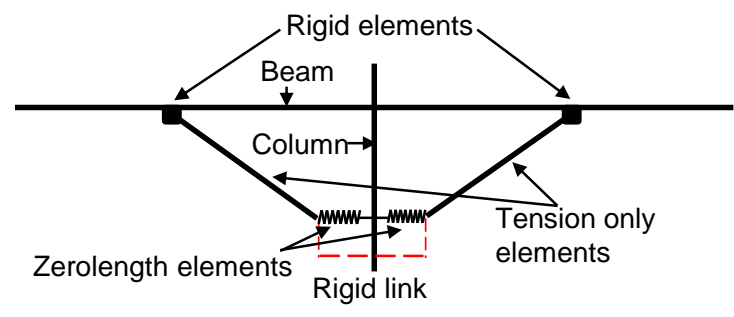

(c)

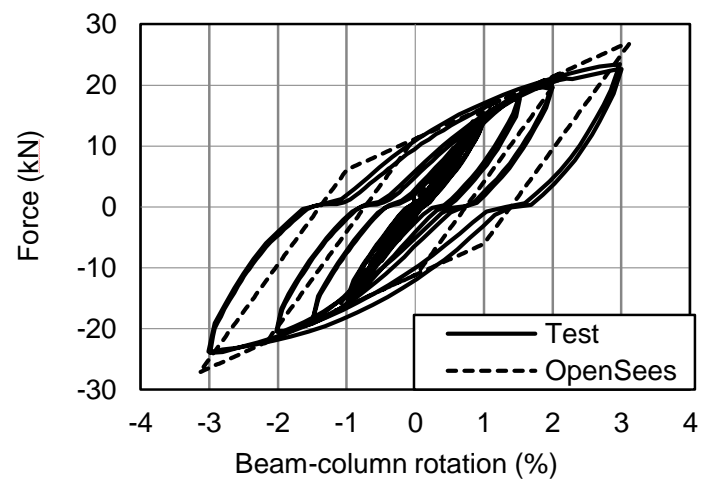

(d)

Figure 12. Building and MDAD model used in OpenSees analysis: (a) front view of four-story bare frame; (b) location of MDADs; (c) details of MDAD model; (d) comparison between OpenSees MDAD model and test result. 


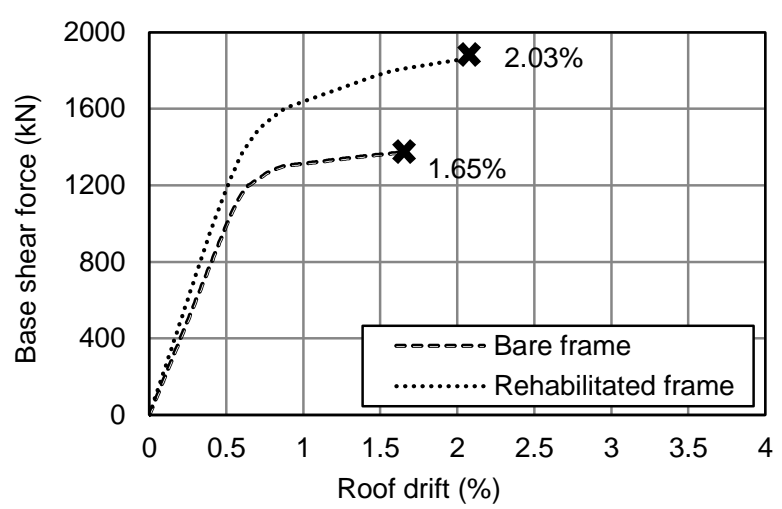

Figure 13. Monotonic pushover.

of the existing frame. This was attained using plate dimensions $360 \mathrm{~mm}$ long, $350 \mathrm{~mm}$ wide and $20.6 \mathrm{~mm}$ thick with SS400 grade steel. The secondary stiffness slope ratio of the plates' assembly was assumed to be 0.3 , as observed in the experiments (see Section 5.1.1). The cross section area of the tension rods was $3847 \mathrm{~mm}^{2}$ with SS400 grade steel.

The modeling of the MDAD is presented in Figure 12(c). It used zero length spring elements with a nonlinear material behavior (steel01 in OpenSees) to model the plate's behavior, and truss elements with tension only behavior for the rods (a combination of ENT material with negative stiffness and an elastic material with positive stiffness in OpenSees). The end joints of the two truss elements used to model the plates were connected with rigid links to ensure the same horizontal displacements, in effect modeling the middle connecting block. Rigid elements were used to account for the eccentricity between the connections of the rods and the centerline of the beam. The hysteresis from the OpenSees MDAD model and experimental results (baseline specimen) are compared in Fig. 12(d). The results compare component level behavior without including the flexibility of other components such as beams and columns. The initial stiffness and yielding strength of two hysteresis matched very well.

\subsection{Monotonic Pushover}

The models of the bare and retrofitted frames were first evaluated using pushover analysis, with an inverted triangle lateral load distribution. Figure 12(a) and (b) show the beam plastic rotations at the left end in radians when the roof drift was $2 \%$. The MDADs effectively reduced the local deformation by $45 \%$. Figure 13 shows the pushover curves attained. The analyses were run until any of the plastic hinges first reached its fracture plastic rotation (i.e., pre-defined as $0.015 \mathrm{rad}$ or $0.022 \mathrm{rad}$ in the positive or the negative directions). In the bare frame, pushover analysis ended at $2.03 \%$ when the plastic rotation at the most left beam end in the second floor reached $0.015 \mathrm{rad}$. In the rehabilitated frame, pushover analysis ended at $2.40 \%$ when the plastic rotation at the most left beam end in the fourth floor reached $0.015 \mathrm{rad}$. By incorporating the MDAD, the stiffness and the strength of the frame yielding first increased by $22 \%$ and $43 \%$, respectively. This is expected to reduce the displacement demanded under earthquakes. Furthermore, the displacement capacity of the frame increased by $23 \%$. This is a very important contribution as many other retrofitting schemes concentrate only on reducing displacement demands. The results also showed that additional stresses induced from the MDAD would not cause undesirable damage modes to the column or beam. The effects of the MDAD significantly enhance structural performance, as will be seen from the nonlinear time history analysis results in the following section. 


\subsection{Time History Analysis}

Nonlinear time history analysis was conducted using the LA $10 \%$ in an assembly of 50 years of ground motions from the SAC Project [Somerville et al., 1997]. For the dynamic analysis, a Rayleigh damping matrix with $2 \%$ damping in the first and second modes was assumed. Table 4 presents the mean plus one standard deviation of important peak responses, including the peak roof drift (roof displacement normalized by the height of the frame), the peak first story drift, the peak first and second story drifts (inter-story drifts normalized by the corresponding height), and the maximum positive and negative plastic rotations over all beam plastic hinges.

Table 4 shows the $84^{\text {th }}$ percentile response quantities under LA10-50 motions for both the bare and rehabilitated frames. As can be seen in Table 4, the bare frame experienced positive plastic rotations as high as $0.022 \mathrm{rad}$, which was larger than the predefined plastic rotation at fracture of $0.015 \mathrm{rad}$. This indicates a need for retrofitting. Implementation of the MDAD reduced these rotations by up to $43 \%$. The addition of the MDAD did not affect drifts as dramatically; however, they decreased on the order of $10 \%$. Thus, the effectiveness of the MDAD is a function of both factors: the increase in strength and stiffness at the structure and story levels, which leads to smaller inter-story drifts, and the reduction in positive plastic rotations even for the same inter-story drift. While the contribution of each factor separately may not be very large, these contributions combine to a considerable improvement in the integrity of the structure. It should also be noted that the negative plastic rotations did not increase, and even decreased somewhat, as a result of using the MDAD. The demand increases in the 1st story columns in terms of forces and bending moments by the attachment of the MDADs are summarized in Table 5 using the 84th percentile responses. The increases in base shear were $29 \%$, which were judged as sufficiently small. The bending moment of the 1st story columns became twice at the location of the MDADs while the top of columns sustained similar bending moments. The columns remained elastic at these locations thanks to an existing reserved strength. The bottom of columns yielded for the both cases and sustained similar bending moments.

Figure 14 presents the roof drift and plastic hinge rotation (the left end $\mathrm{I}_{1}$ of the leftmost beam in the first story, as shown in Figure 12(b)) as a function of time for the bare and retrofitted frames as a response to the LA15 ground motion. With the MDAD, the plastic hinge rotations and global plastic deformations of the frame were efficiently reduced, and fracture at the beam ends was avoided. Furthermore, the residual roof drift was considerable reduced. This is very important because large residual deformations may prevent the ability to restore the structure to its original position after a seismic event, increasing the likelihood of demolition.

\section{CONCLUSIONS}

This paper presents a seismic rehabilitation technique developed under the scheme of minimal-disturbance seismic rehabilitation, which allows the continuous usage of buildings, keeps existing openings and sightlines, and results in minimal increases in force demand to the original framing. To rehabilitate the bottom flanges near the beam-column connections with minimal disturbance, a rehabilitation technique that connected the mid-span of the beam and the upper part of the column with two tension-only rods and energy dissipating steel plates, was developed; the rod-plate connector was termed a minimal-disturbance arm damper (MDAD). The MDAD only uses light steel elements and bolted connections to enable continuity of business during rehabilitation. All elements were placed above three quarters of 
Table 4. Eighty-fourth percentile response quantities under LA10-50 motions.

\begin{tabular}{|c|c|c|c|c|c|}
\hline & $\begin{array}{c}\text { Peak roof } \\
\text { drift [\%] }\end{array}$ & $\begin{array}{c}\text { Peak } 1^{\text {st }} \text { story } \\
\text { drift [\%] }\end{array}$ & $\begin{array}{c}\text { Peak } 1^{\text {st }}+2^{\text {nd }} \\
\text { story drift } \\
{[\%]}\end{array}$ & $\begin{array}{c}\text { Peak hinge } \\
\text { positive } \\
\text { plastic rot } \\
{[\mathrm{rad}]}\end{array}$ & $\begin{array}{c}\text { Peak hinge } \\
\text { negative } \\
\text { plastic rot } \\
{[\mathrm{rad}]}\end{array}$ \\
\hline Bare frame & 1.99 & 2.53 & 2.58 & 0.021 & -0.022 \\
\hline Rehabilitated & 1.84 & 2.20 & 2.12 & 0.012 & -0.020 \\
\hline
\end{tabular}

Table 5. Force demands in first story columns (84th percentile values).

\begin{tabular}{|c|c|c|c|}
\hline & Base shear $[\mathrm{kN}]$ & $\begin{array}{c}\text { Column moment at } \\
\text { MDAD in first story } \\
{[\mathrm{kN} \cdot \mathrm{m}]}\end{array}$ & $\begin{array}{c}\text { Column bottom moment } \\
\text { in first story }[\mathrm{kN} \cdot \mathrm{m}]\end{array}$ \\
\hline Bare frame & $1.60 \times 10^{3}$ & 220.1 & 658.2 \\
\hline Rehabilitated frame & $2.07 \times 10^{3}$ & 457.7 & 657.3 \\
\hline
\end{tabular}

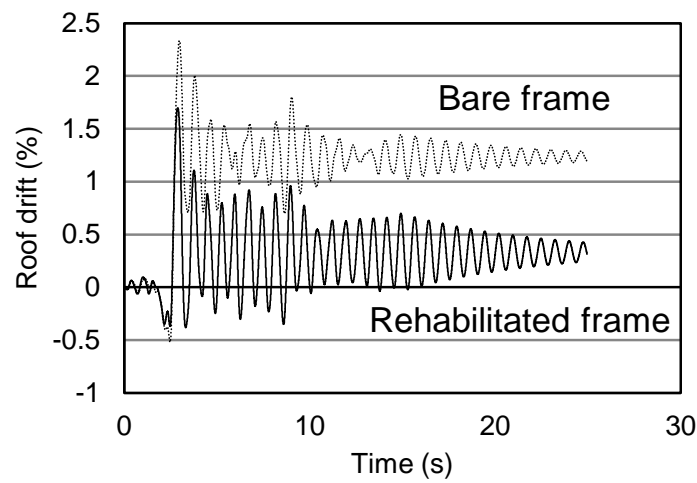

(a)

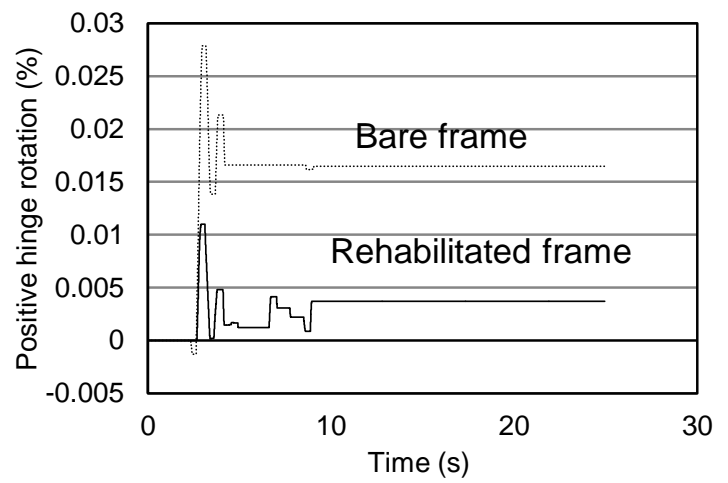

(b)

Figure 14. Time history analysis with and without damper for LA15: (a) roof drift versus time; (b) positive hinge rotation versus time at first story.

600

601

602

603

604

605

606

607

608

609

610

611

612

613

614

615

616

617 the story height to minimize the disturbance to the walking access and sightlines of users of the building.

A baseline model was designed to rehabilitate a beam-column connection in low- to mid-rise steel moment-resisting frames. FE analysis was used to verify the basic load-resisting and energy-dissipating mechanisms intended in the design. The FE analysis was verified with half scale component tests of the MDAD, followed by tests of a full joint connection. After model verification, the response of a four-story building with and without the MDAD was investigated. The major findings are summarized as follows:

(1) In the component level tests, the baseline specimen successfully presented bilinear restoring force characteristics. It was found that the flexibility of connecting blocks induced severe pinching behavior in the force-drift relationship, and this should be avoided in the design. When low yield point steel was used for the energy dissipating bending plates, the system had four times greater energy dissipation than the baseline specimen with conventional steel at $1 \%$ drift. Both the initial stiffness and strength of the rehabilitation system increased when the plates were located farther from the beamcolumn connection. 
(2) When applied to rehabilitate a steel beam-column connection of low-rise steel frames, the rehabilitation technique increased the initial stiffness and the maximum strength by $25 \%$ and $32 \%$, respectively. The bending plates in the energy dissipater yielded at $1.0 \%$ prior to beam yielding at $1.5 \%$.

(3) The full building analysis verified that the effectiveness of the MDAD results from two major factors: the increase in strength and stiffness at the structure and story levels, which leads to smaller inter-story drifts, and the reduction in positive plastic rotations even at the same inter-story drift. It was shown that while the contribution of each factor separately may not be very great, these contributions sum up to a considerable improvement in the integrity of the structure. The $84^{\text {th }}$ percentile maximum peak plastic rotation, under the excitation with a set of ground motions selected from the LA $10 \%$ in 50 years ensemble, reduced by $43 \%$.

(4) For future study, a generalized design procedure will be developed to use MDAD in rehabilitating steel moment-resisting frames with an explicit consideration to reduce positive plastic rotation at the beam ends. Furthermore, it is desirable to develop more effective connecting methods for the attachment of bending plates to the column surface and tension-rod clevises to the beam mid-span.

\section{ACKNOWLEDGMENTS}

Our sincere thanks go to Dr. Kazuhiro Hayashi and Dr. Yundong Shi for their assistance in the experimental work. Support for the sabbatical stay of Oren Lavan was provided by the Disaster Prevention Research Institute, Kyoto University. Funding provided by the Japanese Society for the Promotion of Science to support the post-doctoral research of Tracy Becker is truly appreciated.

\section{REFERENCES}

(1) Nakashima, M., Lavan, O., Kurata, M., Luo, Y.: Earthquake Engineering Research Needs in Light of Lessons Learned from the 2011 Tohoku Earthquake. Earthq. Eng. Eng. Vib., 13, pp. 141-149, 2014.

(2) FEMA-547: Techniques for the Seismic Rehabilitation of Existing Buildings, FEMA, Washington D.C, 2007.

(3) MEXT: Collection of Seismic Rehabilitation Applications, Ministry of Educations, Culture, Sports, Science and Technology Japan, (in Japanese), 2008.

(4) ASCE-41.: Seismic rehabilitation of existing buildings, Reston, VA, Structuring Engineering Institute, American Society of Civil Engineers, 2006.

(5) Kurata, M., Leon, T. R, and DesRoches, R.: Rapid Seismic Rehabilitation Strategy: Concept and Testing of Cable Bracing with Couples Resisting Damper. J. Struct. Eng., 138 (3), pp. 354-362, 2012a.

(6) Kurata, M., Leon. T. R., DesRoches, R., and Nakashima, M. Steel Plate Shear Wall with Tension-Bracing for Seismic Rehabilitation of Steel Frames. J. Const. Steel Research; 71: 92-103, 2012b.

(7) Chung, Y-L., Nagae, T., Matsumiya, T., and Nakashima, M.: Seismic resistance capacity of beam-column connections in high-rise buildings: E-Defense shaking table test. Earthq. Eng. Strut. Dyn., 40(6), pp. 605-622, 2011.

(8) Leon, R. T., Hajjar, J. F., and Gustafson, M. A.: Seismic response of composite momentresisting connections. I: Performance. J. Struct. Eng., 1248, pp. 868-876, 1998. 
666

667

668

669

670

671

672

673

674

675

676

677

678

679

680

681

682

683

684

685

686

687

688

689

690

691

692

693

694

695

696

697

698

699

700

(9) Chen, S-J., Chao, Y.C.: Effect of composite action on seismic performance of steel moment connections with reduced beam sections. J. Const. Steel Research, 57, pp. 417434, 2001.

(10) Kim Y-J, Oh S-H, Moon T-S. Seismic behavior and retrofit of steel moment connections considering slab effects. Engineering Structures; 26(13): pp. 1993-2005, 2004.

(11) Nakashima, M., Matsumiya, T., Suita, K., Liu, D.: Test on Full-scale Three-storey Steel Moment Frame and Assessment of Ability of Numerical Simulation to Trace Cyclic Inelastic Behavior. Earthq. Eng. Strut. Dyn., 35(1), pp. 3-19, 2005.

(12) Suita, K., Nakashima, M., and Engelhardt, M. D. Comparison of Seismic Capacity between Post-Northridge and Post-Kobe Beam-to-column Connections. Proc. Third Inter. Conf. on Behavior of Steel Struct. in Seismic Areas (STESSA 2000), Montreal, pp. 271278, 2000.

(13) AISC: Modification of existing welded steel moment frames for seismic resistance, AISC design guide 12, Chicago, 2009.

(14)FEMA 547: Techniques for the Seismic Rehabilitation of Existing Buildings. Federal Emergency Management Agency. 2008.

(15) Pall, A. S.: Friction devices for aseismic design of buildings. Proc., 4th Canadian Conf. on Earthquake Eng., Canadian National Committee for Earthquake Engineering, Vancouver, Canada, 475-484, 1983.

(16) Anagnostides, G., Hargreaves, A. C., and Wyatt, T. A.: Development and applications of energy absorption devices based on friction. J. Constr. Steel Res., 13(4), 317-336, 1989.

(17) Mualla, I. H., and Belev, B.: Performance of steel frames with a new friction damper device under earthquake excitation.” Eng. Struct., 24(3), 365-371, 2002.

(18) Kang, J. D., and Tagawa, H.: Seismic response of steel structures with seesaw systems using visoelastic dampers.” Earthq. Eng. Strut. Dyn., 42(5), pp. 779-794, 2012.

(19)Dassault Systems: Abaqus Analysis User's Manual ABAQUS 6.10, Dassault Systèmes Simulia Corp., Providence, RI, USA, 2010.

(20)Chopra, A., Dynamics of structures, Theory and Applications to Earthquake Engineering, Prentice-Hall of India, 2001.

(21)Mazzoni, S., McKenna, F., Scott, M. H., Fenves, G. L. (2009). Open system for earthquake engineering simulation: User command language manual, PEER, Univ. of CA, Berkeley.

(22) Somerville, P. G., Smith, N., Punyamurthula, S. and Sun, J. Development of ground motion time histories for phase 2 of the FEMA/SAC Steel Project. Report SAC/BD-97/04, SAC Joint Venture. 1997. 